\title{
What Do We Know About the Drivers of Health and Equity? A Narrative Review of Graphic Representations
}

\author{
Marjory L. Givens, ${ }^{*} \dagger$ Bridget B. Catlin, ${ }^{\dagger}$ Sheri P. Johnson, Elizabeth A. Pollock, Victoria N. Faust, \\ Paula Tran Inzeo, and David A. Kindig
}

\begin{abstract}
Purpose: Frameworks can be influential tools for advancing health and equity, guiding population health researchers and practitioners. We reviewed frameworks with graphic representations that address the drivers of both health and equity. Our purpose was to summarize and discuss graphic representations of population health and equity and their implications for research and practice.

Methods: We identified publicly available frameworks that were scholarly or practice oriented and met defined inclusion and exclusion criteria. The identified frameworks were then described and coded based on their primary area of focus, key elements included, and drivers of health and equity specified.

Results: The variation in purpose, concepts, drivers, underlying theory or scholarly evidence, and accompanying measures was highlighted. Graphic representations developed over the last 20 years exhibited some consistency in the drivers of health; however, there has been little uniformity in depicting the drivers of equity, disparities or interplay among the determinants of health, or transparency in underlying theories of change.

Conclusion: We found that current tools do not offer consistency or conceptual clarity on what shapes health and equity. Some variation is expected as it is difficult for any framework to be all things to all people. However, keeping in mind the importance of audience and purpose, the field of population health research and practice should work toward greater clarity on the drivers of health and equity to better guide critical analysis, narrative development, and strategic actions needed to address structural and systemic issues perpetuating health inequities.
\end{abstract}

Keywords: social determinants of health; determinants of equity; graphic representations

\section{Introduction}

In the early 1990s, two broad conceptual frameworks for considering the factors that influence health were published. ${ }^{1,2}$ These two examples of frameworks continue to guide the work of population health researchers and practitioners. Graphic representations, such as conceptual frameworks, are often used to help clarify and distill a set of concepts that are fundamental and their relationship to a phenomenon. Conceptual frameworks are particularly important when a single theory, theoretical framework, or perspective is deemed insufficient to capture a complex phenomenon. In research, conceptual frameworks shape the epistemological paradigm-or belief systems for how and why we know the worldbrought to the phenomena of interest. Conceptual frameworks can help guide the framing of research projects, how relevant questions are determined, how meaning is attached to data, and the resulting development of research findings. Similarly, in practice, such frameworks can help shape how people consider and approach the

Population Health Institute, School of Medicine and Public Health, University of Wisconsin-Madison, Madison, Wisconsin, USA.

Co-first authors.

*Address correspondence to: Marjory L. Givens, PhD, Population Health Institute, School of Medicine and Public Health, University of Wisconsin-Madison, 610 Walnut Avenue, Madison, WI 53726, USA, E-mail: mgivens@wisc.edu

(C) Marjory L. Givens et al., 2020; Published by Mary Ann Liebert, Inc. This Open Access article is distributed under the terms of the Creative Commons License (http://creativecommons.org/licenses/by/4.0), which permits unrestricted use, distribution, and reproduction in any medium, provided the original work is properly cited. 
identification and prioritization of problems to be addressed, identify and interpret relevant data and research findings, and implement and evaluate solutions. Such frameworks, therefore, have the potential to affect how we collectively understand, investigate, and address societal and community issues.

Population health is one such complex phenomenon for which both researchers and practitioners have developed and graphically represented frameworks. The graphic representations of these frameworks show a broad picture of health and its drivers that go beyond simply defining health as the absence of disease and health care as the primary driver of health. A collection of these frameworks, representing a continuously expanding set of determinants that influence health, was reviewed in 2015 by the Canadian Council on Social Determinants of Health (CCSDH). ${ }^{3}$

Many of the frameworks in the CCSDH review do not, however, specifically address the factors that influence how determinants of health and their related health outcomes are distributed within and across communities (or populations). We define such factors that shape the distribution of determinants and, subsequently, health outcomes as drivers of equity. As McCartney et al. ${ }^{4}$ noted, scholars have offered multiple definitions of health equity over the years. For the purposes of this review, we follow Whitehead's 1992 definition: "Equity in health implies that ideally everyone should have a fair opportunity to attain their full health potential and, more pragmatically, that none should be disadvantaged from achieving this potential." More recently, new frameworks and associated graphic representations of health have emerged that do attempt to incorporate drivers of equity in the context of health, such as the World Health Organization's (WHO's) Commission on the Social Determinants of Health $(\mathrm{CSDH})$ conceptual framework ${ }^{6}$ and the Bay Area Regional Health Inequity Initiative (BARHII). ${ }^{7}$ We find such frameworks to be important to a field that increasingly prioritizes examination of the distribution of determinants and, subsequently, health outcomes across communities. We therefore set out to review such frameworks.

Similar in approach to the CCSDH review, this essay discusses graphic representations of frameworks of drivers of health and equity. It differs from the CCSDH review in that it centers inclusion criteria on the drivers of equity (or inequity or inequalities). Given the focus on graphic representations, it does not review an exhaustive catalog of frameworks used to explain drivers of health, nor does it include frameworks that represent drivers of equity outside a health context. Our emphasis on the drivers of health and equity is also different from another Canadian review by the National Coordinating Center for Determinants of Health, which focused on knowledge to action models. ${ }^{8}$ In addition, it is not designed as a formal evaluation of the frameworks reviewed. Rather, the purpose of this review is to stimulate discussion on how frameworks (describing relevant concepts and their relationships for study of a topic ${ }^{9}$ ) or models (descriptions or analogies used to help visualize something that cannot be directly observed ${ }^{10}$ ) shape understanding of knowledge and principles used in population health research and practice and how we collectively understand the drivers of health and equity in our work.

\section{Methods}

Our approach for this work went beyond what is normally applied for a traditional narrative review (see, e.g., the University of Alabama-Birmingham's comparison of systematic and narrative reviews), particularly around inclusion/exclusion criteria, which are seldom reported for narrative reviews. Our approach also differed from other systematic and narrative reviews in that we were searching for graphical depictions rather than original research studies. So, to identify existing frameworks that address the drivers of health and equity, our initial search strategy involved using Google, PubMed, and Google Scholar from March 2019 to January 2020 for English-language documents and images based on the following keywords: (determinants of health OR wellbeing) AND (health equity OR health inequalities) AND (frameworks OR models OR theories). We followed up with snowball sampling from citations of documents found and searches of relevant organizational websites, reports, and gray literature were also reviewed. We conducted a broad, but not exhaustive, search for frameworks that were published in the 21st century when materials became more widely available on the internet. We did not focus our search on formal research databases because we were particularly interested in finding images of frameworks that have been used in practice.

From these materials, we selected frameworks for review that were scholarly or practice oriented and met the following inclusion criteria:

- Must mention equity or like terms (inequity, inequality, disparities, and differences across groups): for example, several well-known or emerging frameworks do not mention equity or like terms. ${ }^{1,2,11-14}$ 
- Must include a graphical depiction of the drivers of health equity: for example, Braveman has written extensively about health equity, but we were unable to find a conceptual framework in her work. Similarly, the new Well-being in the Nation Measures ${ }^{15}$ did not include a graphic at the time of retrieval.

- Must include specific drivers of health equity (e.g., education and employment): for example, Chang ${ }^{16}$ only lists general drivers of equity (e.g., opportunities and barriers).

- Must include arrows, nesting, sequencing, or other graphical approaches to show drivers' relationships to equity: for example, King County's 14 Determinants of Health Equity ${ }^{17}$ provides a comprehensive listing of determinants (or drivers) of health equity, but does not show how they relate to equity, health, or each other.

- Must address general health/equity, not specific topics such as drivers of asthma, behavioral medicine, and gender equity: for example, Gee and Payne-Sturges's framework ${ }^{18}$ is specific to environmental health disparities.

- Must focus on frameworks addressing drivers of health/equity rather than frameworks focused on actions to improve health/equity: for example, the frameworks reviewed by Davison et al. ${ }^{8}$

Frameworks were excluded from the sample if they were not posted on the internet or if they represented derivatives of included frameworks. For example, several organizations have published modified versions of the $\mathrm{WHO} \mathrm{CSDH}^{4}$ and BARHII ${ }^{7}$ frameworks. Inclusion criteria were developed collaboratively among the authors, based on disciplinary and practical knowledge. Results are expected to inform discussion in the field on what shapes health and equity, how it is graphically portrayed, and the implications for our research and practice.

Once we had selected frameworks to be included in our review, one co-author extracted information directly from applicable articles or websites and another co-author checked the extraction to be sure we accurately recorded information about the frameworks. Following discussions with all the authors that led to the development of a list of key background information and elements, we then conducted a qualitative review of the frameworks with two co-authors coding information independently and then reconciling differences in interpretation of frameworks and background information. The lead author served as the final arbiter for any difference not reconciled. Our intent was to be sure that we reported shared, rather than individual, interpretations of information reflected in the frameworks. We coded the following information:

- Primary area of focus:

- Community practice (local health assessment and improvement)

- Policy development (supporting national or state decision making), and/or

- Research.

- Key elements:

What is in the framework:

1. Role of individuals and communities in driving health and equity (CCSDH also captured this element in their review ${ }^{3}$ )

2. Identifies fundamental causes of inequity

3. Mentions multiple disparity domains (e.g., race and SES).

How do things relate:

4. Shows interactions between determinants (CCSDH also captured this element in their review ${ }^{3}$ )

5. Recognizes inequities in determinants and/or policies (as well as outcomes)

Salience, credibility, and legitimacy:

6. Based on peer-reviewed literature (e.g., material supporting the framework includes citations)

7. Recognition of importance of upstream action (CCSDH also captured this element in their review ${ }^{3}$ )

8. Includes some metrics.

Given that graphical depictions of frameworks are frequently designed to be used outside the accompanying text and so often stand alone, or in isolation of context, our qualitative review involved coding frameworks without consulting accompanying text. The only exceptions made were for elements 6 and 8. As noted above, three of the key elements were drawn from the CCSDH review. The remaining key elements were identified based on discussion among the co-authors about potentially desirable criteria for a framework depicting the drivers of health and equity.

After this qualitative review, we captured and coded the drivers of health and equity listed in each framework. Two co-authors performed the coding and then discussed and reconciled the initial results together. All the co-authors met to review and finalize the coding schema. Drivers were coded into major categories and subcategories to tally counts within each grouping. 


\section{Results}

We found 27 health and equity frameworks that met our inclusion and exclusion criteria, described in Table 1. These frameworks are listed in chronological order with the year of initial publication, names of the authoring individuals or organizations, framework or article title, country of origin, stated purpose and target audience, stated context and origins (with underlying explicit or implicit theory if clearly articulated), and source.

The year of initial publication of the frameworks reviewed ranged from 2001 to 2019. Of those identified, more frameworks (seven) were published in 2015 than in any other year. Sixteen of the frameworks (59\%) were developed in the United States, with the remaining frameworks coming from Australia, Canada, and Europe. Eight of the frameworks were published in peer-reviewed literature with the remaining 19 (70\%) coming from gray literature. More than half of the frameworks were published by government entities (national, regional, or local). Eight of the frameworks were either developed by the WHO's Commission on Social Determinants or were influenced by their work; and of these, all but one was developed outside the United States. While few of the framework descriptions clearly articulated their underlying theories, the theories mentioned in the WHO work included ecosocial, psychosocial, and social production of disease/political economy of health. Other theories mentioned included fundamental causation and life course. Principles of social justice and human rights were also mentioned in a minority of the framework descriptions.

Tables 2 and 3 provide the results of our qualitative review of the 27 frameworks. With their concentration in the scholarly and gray literature, we identified frameworks with a variety of primary areas of emphasis, the most common of which was policy development. The early frameworks (from 2001 to 2004) that we found were intended to guide policy development or research. The first frameworks for community practice did not appear until 2008. Many of the frameworks intended to guide research did not appear until 2015.

Two-thirds of the frameworks were framed positively, that is, their outcomes were stated in terms of well-being or equity. Outcomes in the remaining onethird of the frameworks were framed negatively, comprising terms such as inequity or disparity.

We found that at least 22 (or $81 \%$ ) frameworks drew from peer-reviewed literature-this was the most common key element identified among the frameworks. The next most frequent key element was the inclusion of some metrics, which we found for 17 (63\%) of the frameworks. Examples of metrics include measures such as age-adjusted mortality rates, percent of population under the federal poverty level, and the Gini coefficient as an income inequality metric. Beyond acknowledging that there are inequities in health outcomes, over half of the frameworks also recognized the existence of inequities in determinants or policies (16 total or 59\%) or highlighted the importance of upstream action ( 15 total or $56 \%$ ). Just over half of frameworks reviewed acknowledged multiple disparity domains (14 total or 52\%), such as among racial/ethnic groups, socioeconomic status, or by age groups.

The least frequently classified key elements were highlighting the roles of individuals and communities (found in only $37 \%$ of frameworks), interaction between determinants (37\%), and identifying fundamental causes of inequity (33\%).

Frameworks developed to serve as a guide to future research are likely to be subject to different criteria than frameworks designed to guide community practice. Thus, given the different purposes of the frameworks, it is not surprising that no single framework included all the key elements. The frameworks with the most key elements was Schulz and Northridge's, ${ }^{19}$ which includes all the key elements, except for mentioning multiple disparity domains, and the Public Health Agency of Canada's, ${ }^{20}$ which includes all elements, except for showing interactions between the determinants of health and equity. Three frameworks include all but two key elements: Centers for Disease Control and Prevention's Promoting Health Equity ${ }^{21}$ (missing were identifying fundamental causes of inequity and the importance of upstream actions), the WHO CSDH frameworks ${ }^{6}$ (missing were role of individuals and communities and identifying fundamental causes), and Victorian Health Promotion Foundation's framework ${ }^{22}$ (missing identifying fundamental causes of inequity and showing interactions between determinants).

Three frameworks included only one of the key elements we identified: the Winnipeg Regional Health Authority $^{23}$ and the National Institute of Minority Health and Health Disparities ${ }^{24}$ frameworks, which were both based on peer-reviewed literature, and the Colorado Department of Public Health framework, ${ }^{25}$ which included some metrics.

In Table 4, we display a summary of the various drivers, sometimes termed determinants, of health and equity found in the frameworks reviewed. We listed drivers that were found in at least three of the frameworks in bold text. At the highest level, we coded drivers that addressed 


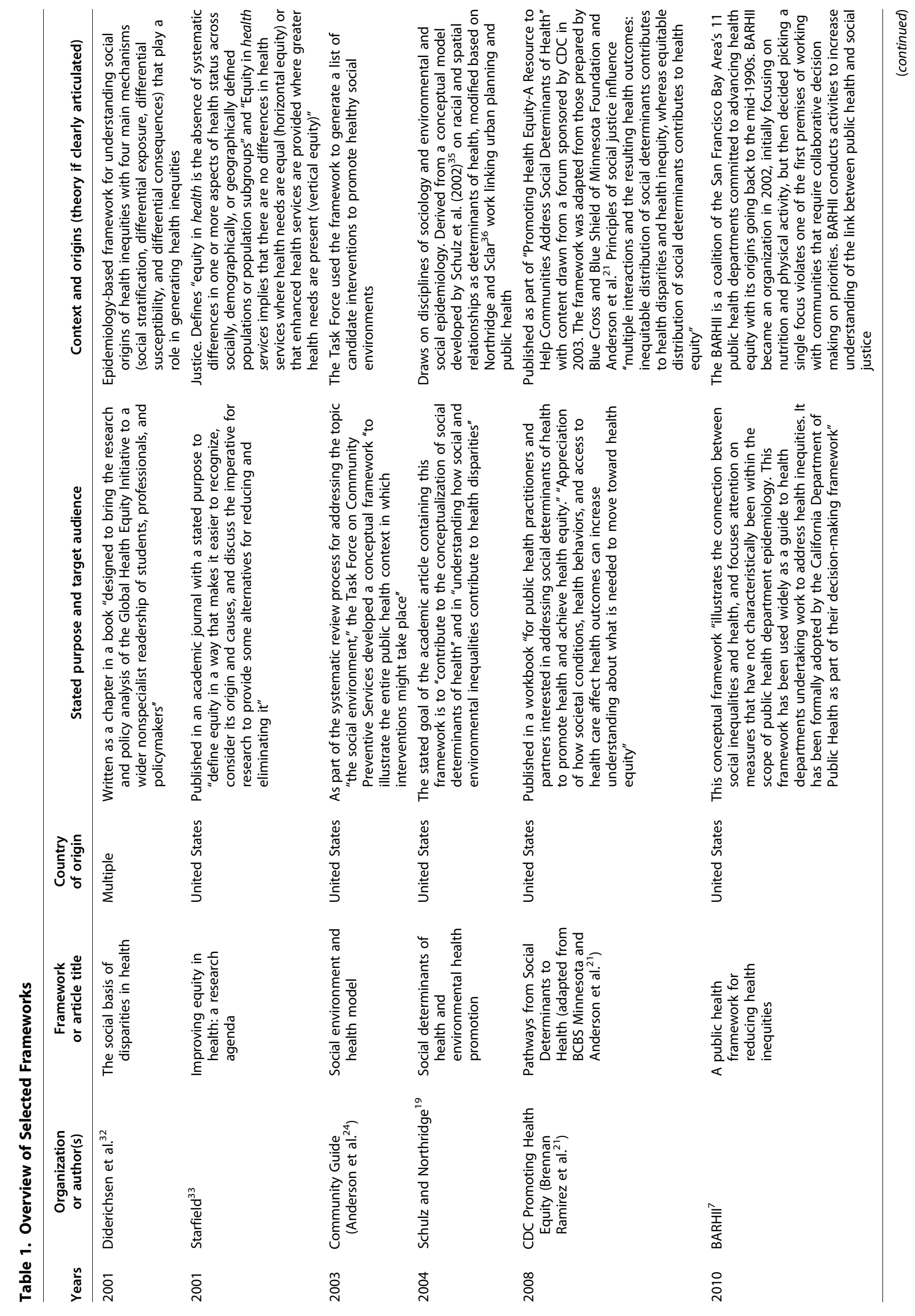




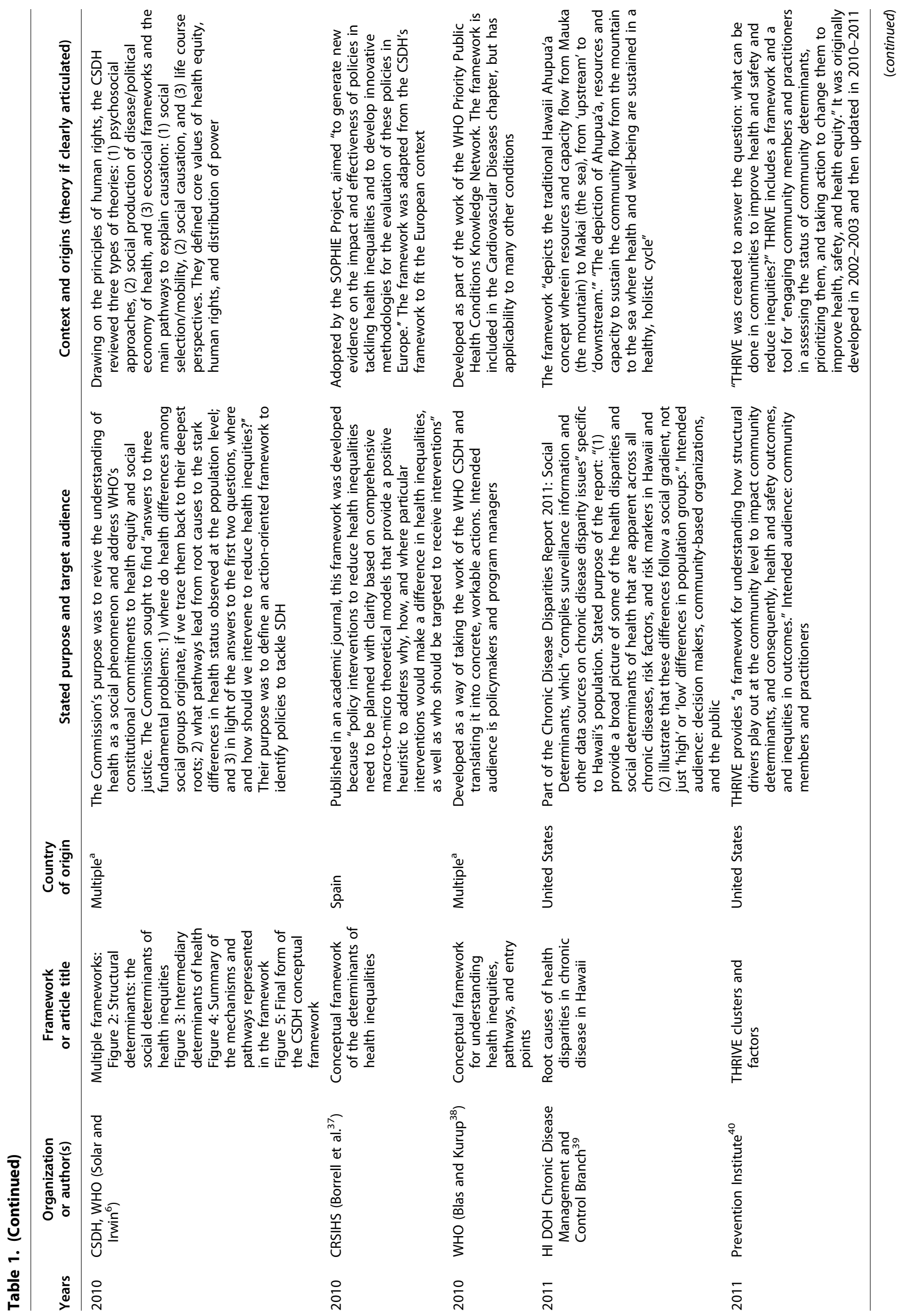




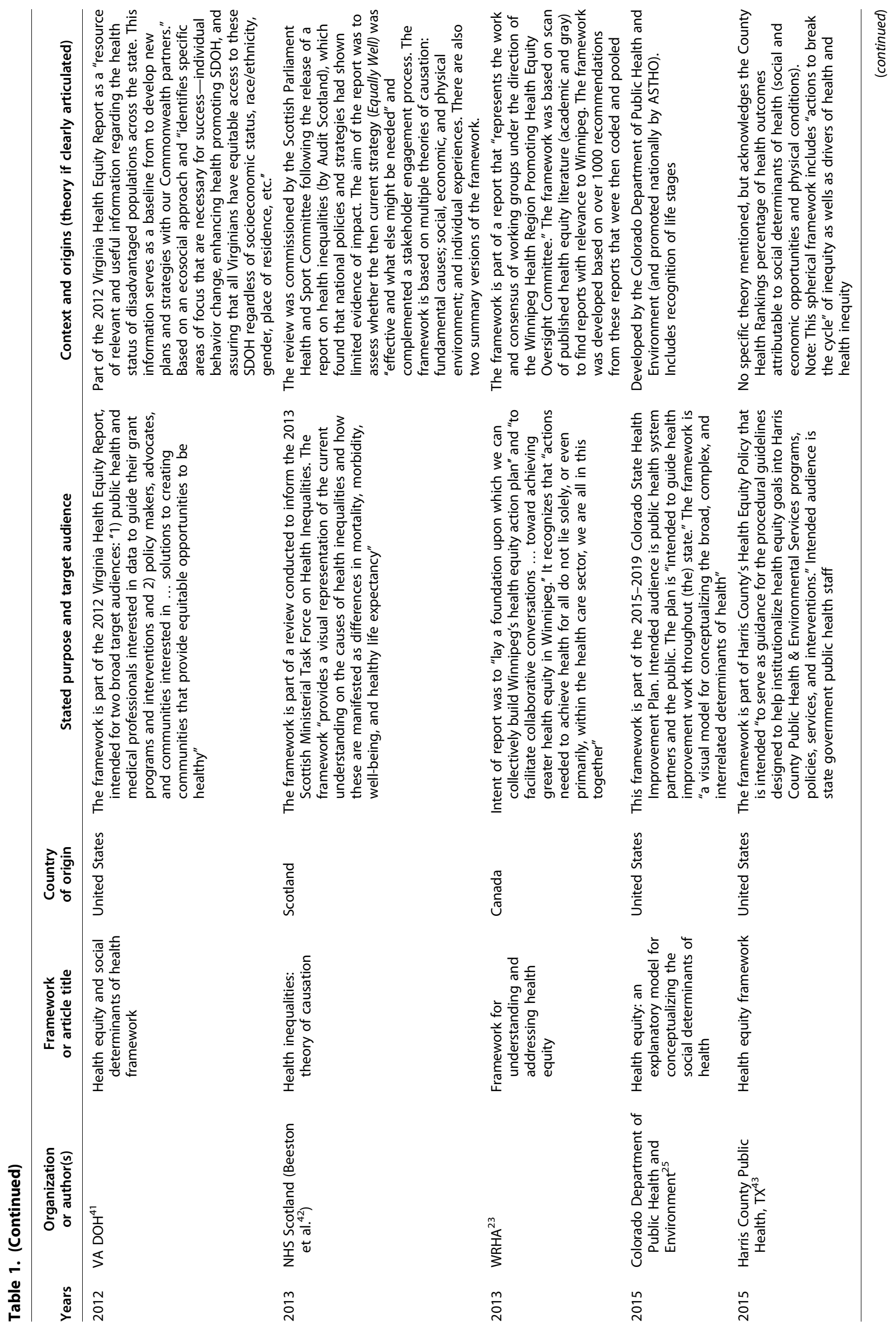




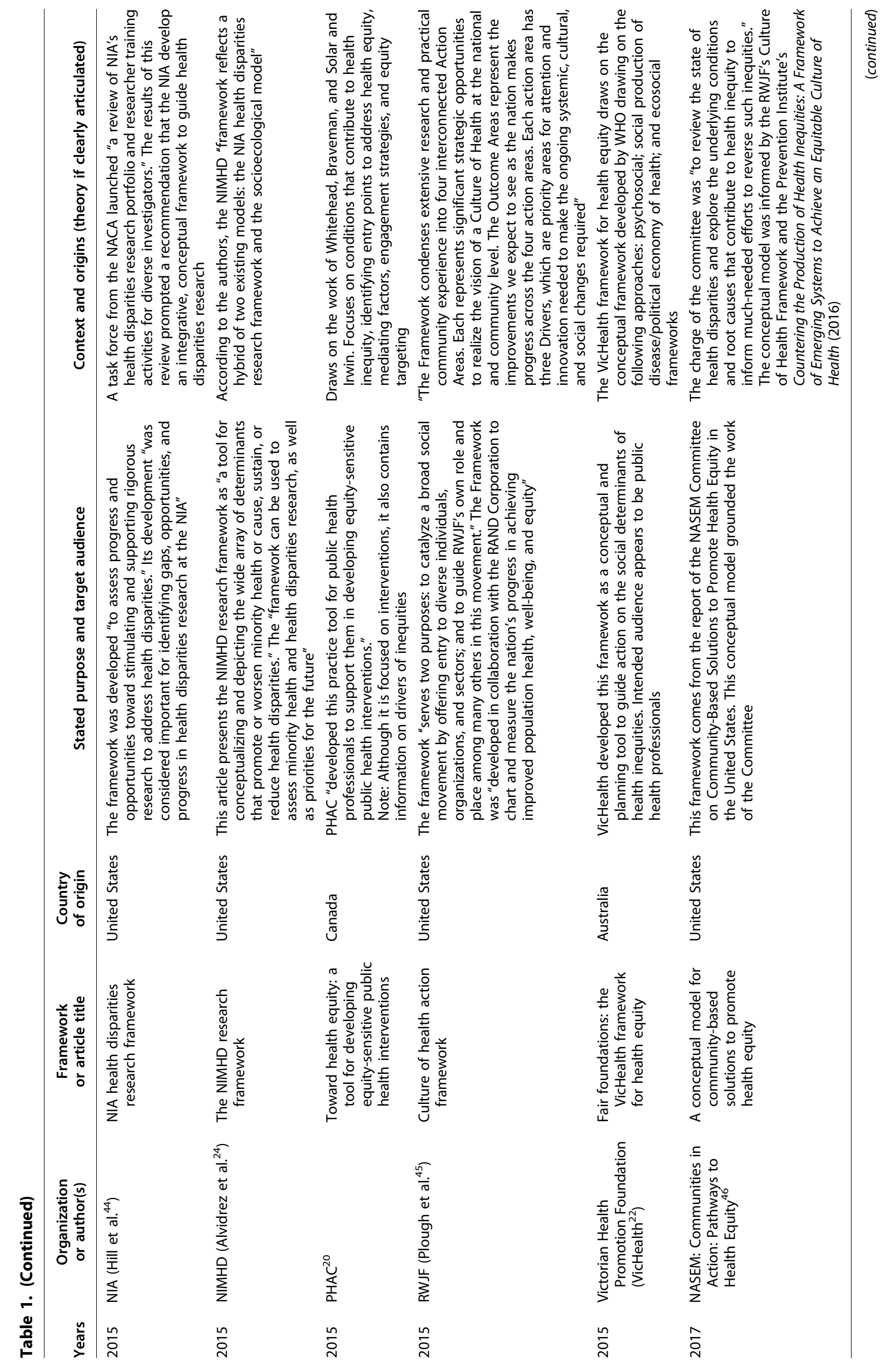




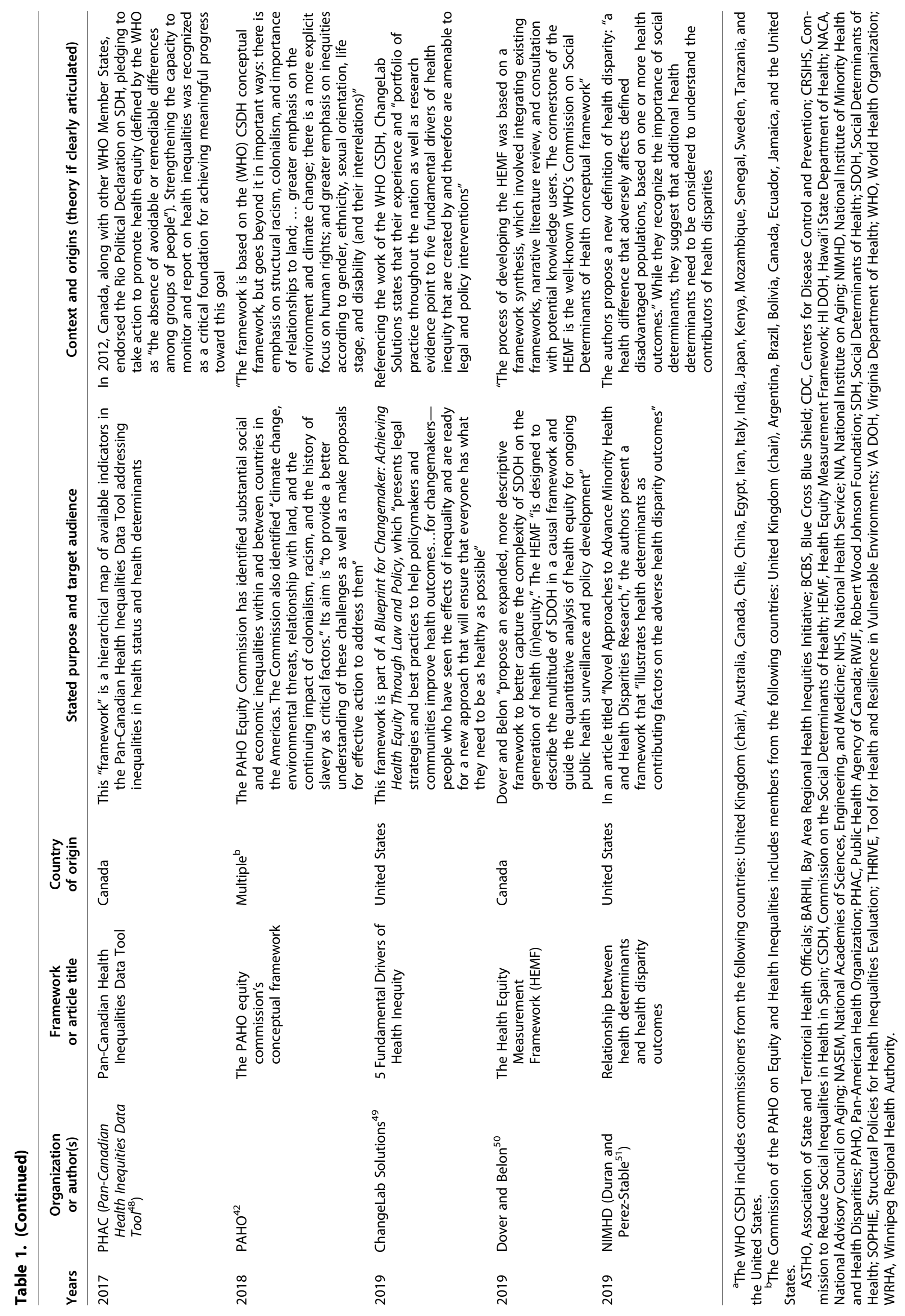


Table 2. Primary Area of Focus of Selected Frameworks

\begin{tabular}{|c|c|c|c|c|c|}
\hline Years & Organization or author(s) & Framework & $\begin{array}{l}\text { Community } \\
\text { practice }\end{array}$ & $\begin{array}{c}\text { Policy } \\
\text { development }\end{array}$ & Research \\
\hline 2001 & Diderichsen et al. ${ }^{32}$ & The social basis of disparities in health & & $x$ & \\
\hline 2001 & Starfield ${ }^{33}$ & Improving equity in health: a research agenda & & & $x$ \\
\hline 2003 & Community Guide ${ }^{34}$ & Social environment and health model & & $\times$ & \\
\hline 2004 & Schulz and Northridge ${ }^{19}$ & $\begin{array}{l}\text { Social determinants of health implications for environmental } \\
\text { health promotion }\end{array}$ & & & $x$ \\
\hline 2008 & CDC Promoting Health Equity ${ }^{21}$ & Pathways from social determinants to health & $x$ & & \\
\hline 2010 & BARHII $^{7}$ & A public health framework for reducing health inequities & $x$ & & \\
\hline 2010 & WHO CSDH ${ }^{6}$ & Multiple frameworks & & $x$ & \\
\hline 2010 & $\mathrm{CRSIHS}^{37}$ & $\begin{array}{l}\text { Conceptual framework of the determinants of health } \\
\text { inequalities }\end{array}$ & & $x$ & \\
\hline 2010 & $\mathrm{WHO}^{38}$ & $\begin{array}{l}\text { Conceptual framework for understanding health inequities, } \\
\text { pathways, and entry points }\end{array}$ & & $x$ & \\
\hline 2011 & $\mathrm{HI} \mathrm{DOH}^{39}$ & Root causes of health disparities in chronic disease in Hawaii & $x$ & & \\
\hline 2011 & Prevention Institute $e^{40}$ & THRIVE factors & $x$ & & \\
\hline 2012 & VA DOH ${ }^{41}$ & Health equity and social determinants of health framework & $x$ & $x$ & \\
\hline 2013 & NHS Scotland ${ }^{42}$ & Health inequalities: theory of causation & $x$ & $x$ & \\
\hline 2013 & WRHA ${ }^{23}$ & Framework for understanding and addressing health equity & $x$ & $x$ & \\
\hline 2015 & $\mathrm{CO} \mathrm{DPH}^{25}$ & $\begin{array}{l}\text { Health equity: an explanatory model for conceptualizing the } \\
\text { social determinants of health }\end{array}$ & $x$ & $x$ & \\
\hline 2015 & Harris County Public Health, $\mathrm{TX}^{43}$ & Health equity framework & & $x$ & \\
\hline 2015 & $N I A^{44}$ & NIA health disparities research framework & & & $x$ \\
\hline 2015 & NIMHHD ${ }^{24}$ & The NIMHHD research framework & & & $x$ \\
\hline 2015 & $\mathrm{PHAC}^{20}$ & $\begin{array}{l}\text { Toward health equity: a tool for developing equity-sensitive } \\
\text { public health interventions }\end{array}$ & $x$ & $x$ & \\
\hline 2015 & RWJF $^{45}$ & Culture of health action framework & & $x$ & $x$ \\
\hline 2015 & $\begin{array}{l}\text { Victorian Health Promotion } \\
\text { Foundation (VicHealth) }\end{array}$ & Fair foundations: the VicHealth framework for health equity & $x$ & $x$ & \\
\hline 2017 & $\begin{array}{l}\text { NASEM: Communities in Action: } \\
\text { Pathways to Health Equity }{ }^{46}\end{array}$ & $\begin{array}{l}\text { A conceptual model for community-based solutions to } \\
\text { promote health equity }\end{array}$ & $x$ & $x$ & \\
\hline 2017 & $\mathrm{PHAC}^{47}$ & Pan-Canadian Health Inequalities Data Tool & $x$ & & $x$ \\
\hline 2019 & $\mathrm{PAHO}^{48}$ & The PAHO Equity Commission's Conceptual Framework & & $x$ & $x$ \\
\hline 2019 & ChangeLab Solutions ${ }^{49}$ & 5 Fundamental drivers of health inequity & $x$ & $x$ & \\
\hline 2019 & Dover and Belon ${ }^{50}$ & The Health Equity Measurement Framework (HEMF) & & $x$ & $x$ \\
\hline \multirow[t]{2}{*}{2019} & NIMHHD ${ }^{51}$ & $\begin{array}{l}\text { Relationship between health determinants and health } \\
\text { disparity outcomes }\end{array}$ & & & $x$ \\
\hline & & Totals & 13 & 17 & 9 \\
\hline
\end{tabular}

CO DPH, Colorado Department of Public Health.

(1) individual characteristics, (2) community conditions and community context, (3) societal context, and (4) overarching drivers, that is, which can occur at the individual, community, or societal level. Within each of these five categories, we identified up to six subcategories of drivers of health and equity. The subcategories and drivers are listed in alphabetical order.

In Table 5, we display the assigned categories and subcategories for the drivers included in each of the frameworks reviewed. Eleven of the frameworks listed drivers of health and equity that covered all four categories (subcategories): individual characteristics (awareness, beliefs, and worldview; biology and genetics; health behaviors; individual experience, identity, and social position; individual experience and life course; psychological, risk and resilience, and sense of belonging; and socioeconomics), community conditions and context (community assets; community assets-health care; characteristics of assets/services; environment built/natural; environment- economic, employment; environment-social, political, and cultural, history), societal context (civic muscle; crisis and chronic conditions; environment-economic, employment; environment-social, political, and cultural; policies and law; and societal values and norms), and overarching drivers (fundamental drivers of inequities; resources and allocation; and rights). Community conditions and context was the only category where all frameworks included at least one driver. The overarching category was the least common category, with only 15 frameworks including at least one driver.

The most frequent subcategories identified were environment-social, political, and cultural (under community context, included in 24 out of $27 \%$ or $89 \%$ of frameworks), community assets and environment-built or natural (under community context, each included in $78 \%$ of frameworks), and individual experience, identity, and social position (under individual characteristics, included in $74 \%$ of frameworks). 


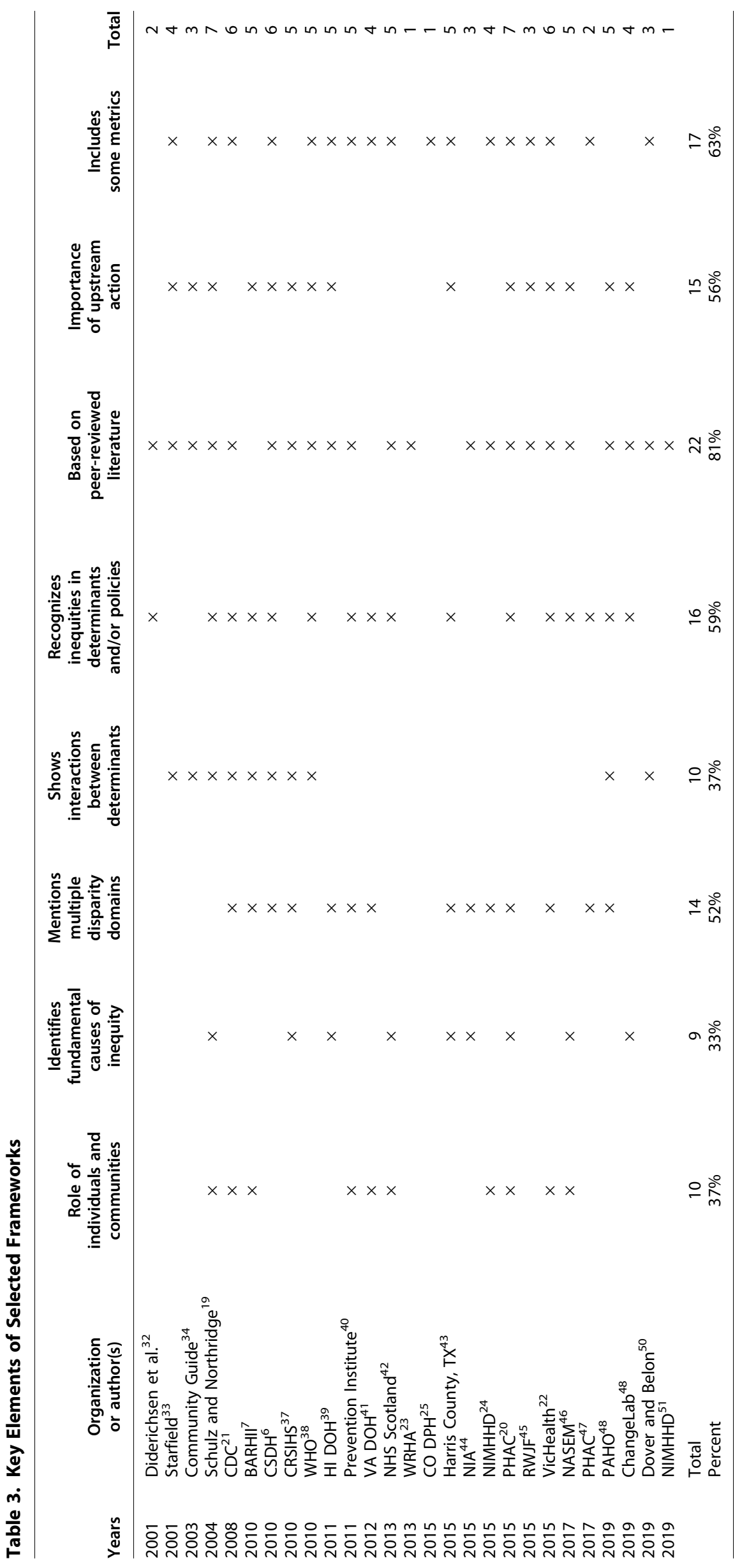




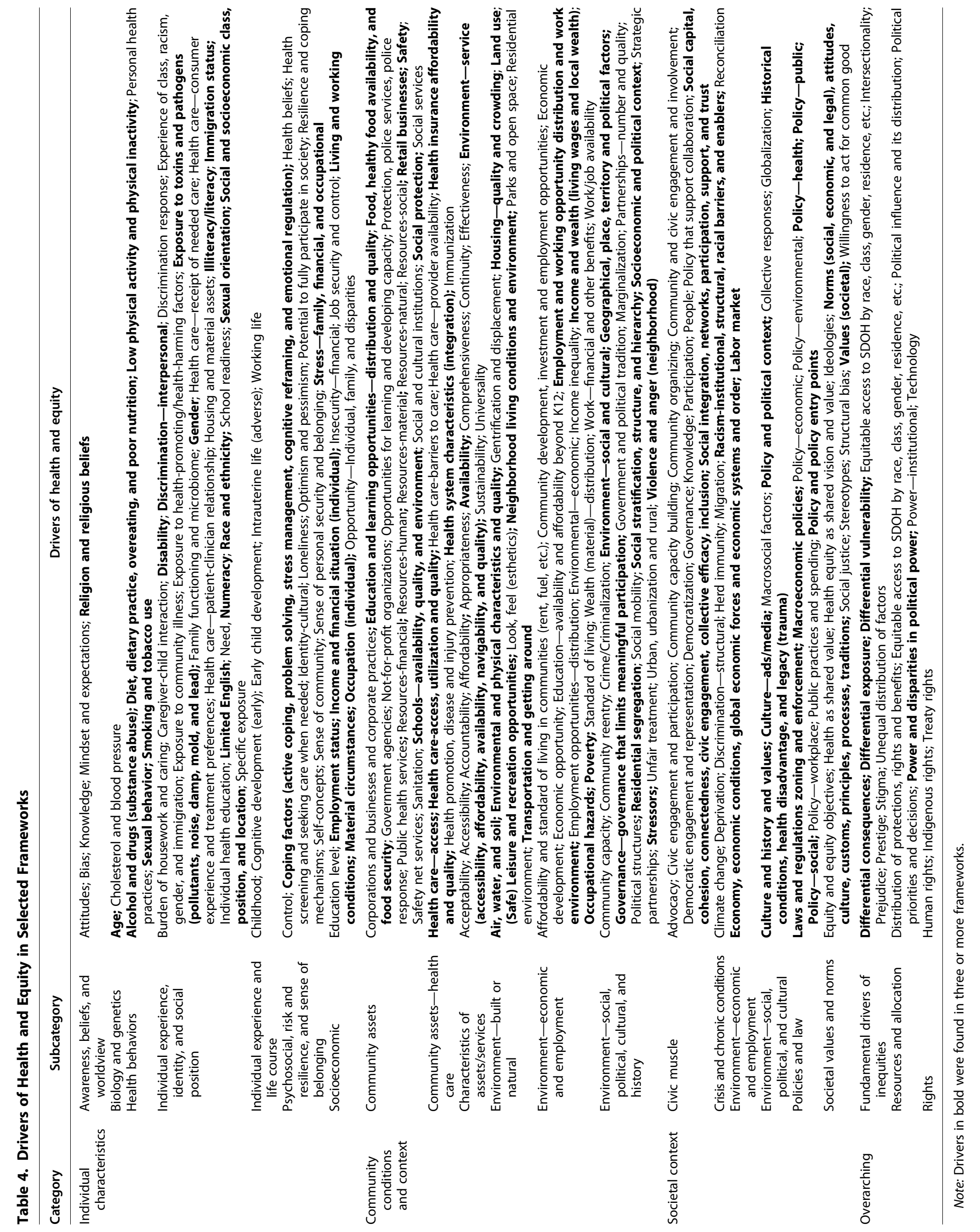




\section{Discussion}

We believe that frameworks can serve many purposes: they can inform research agendas, planning and decision making, or assessment. Frameworks can be considered boundary-spanning tools to engage new audiences among disciplines, sectors, or community groups. For example, the County Health Rankings measurement framework has helped advance conversation about the social determinants of health. ${ }^{12}$ Frameworks are also intended to organize thinking and shape narratives, which in turn shape the boundaries of what is possible for action. And frameworks can also be used to help raise awareness and make sense of the issues that shape health and equity.

We found many more frameworks than the 27 frameworks that met our criteria. The low number was both a reflection of our search approach and the stringency of our selection criteria. Several published frameworks that we found, but did not include, are derivatives of other frameworks and, as such, did not meet our inclusion criteria for review.

In terms of purpose, the focus of frameworks that we found from outside the United States was more likely to be on policy development. And, of the key elements, the non-United States frameworks were more likely to mention multiple disparity domains and recognize inequities in determinants and policies. However, the real benefit of including frameworks from outside the United States was the additional richness provided by the types of drivers of health and equity that they included.

Only eight of the frameworks were published in peerreviewed publications and research was the stated purpose of most of these frameworks, that is, none of the eight were intended to guide community practice. However, we were heartened to see that many of the frameworks intended to guide community practice found in the gray literature were based on peer-reviewed literature. The linkage between scholarly work and practice continues to be important.

Recent dialogue about equity in the field of population health has focused on the importance of an assetoriented approach, or positive framing. Asset-oriented approaches serve to counter the negative default assumptions about communities that bear disproportionate burden of inequitable conditions. However, it is not clear whether this approach is more likely to change the way equity is studied or practiced. Most of the frameworks reviewed were positively framed, none provided comprehensive metrics that quantify assets that influence health or measurement of equitable outcomes-a recognized current limitation in the field. ${ }^{26}$ For those positively framed, it is also unclear how to deal with historical policy and practice that underlie inequity, such as assimilation laws aimed at Native Americans and Jim Crow laws. Furthermore, some (positively or negatively framed) frameworks illustrate what should be measured, while others only illustrate what can currently be measured. For example, several frameworks include constructs that should be measured, such as civic engagement or political factors, whereas, in reality, what can be measured may be limited to metrics such as voter participation.

Given that equity is a comparative principle, or judgment about how a person or group of people is situated relative to others, it is intriguing that very few, if any, frameworks were explicit about underlying theories, values, and norms that provide context for sense making of what is avoidable, unfair, and unjust. The absence of clear guidance about whether and how conditions are unjustly produced, raises questions about utility for deriving innovative scholarship or practice.

As the field embraces intersectionality, frameworks will also need to evolve to acknowledge interactions among determinants and interconnections of multiple disparity domains. Few frameworks effectively did so among those we reviewed. While identifying many of the known relationships and interactions between components of a framework is important to guide future research, showing all such relationships in a framework intended to guide community practice can be confusing, sometimes described as arrow soup. Conversely, failing to show important interactions can lead to misunderstanding at the least, or far worse, could lead decisionmakers, practitioners, or communities to overinvest or underinvest in resources in the most impactful or intertwined factors that could improve health and equity.

One potential way to focus attention on the most important interactions is to identify fundamental or root causes of health and equity, sometimes referred to as the "causes of the causes" or "upstream of the upstream." Fundamental cause theory was developed by Link and Phelan ${ }^{27}$ who proposed four essential features for a fundamental social cause of health inequalities:

1. It influences multiple disease outcomes, meaning that it is not limited to only one or a few diseases or health problems.

2. It affects these disease outcomes through multiple risk factors.

3. It involves access to resources that can be used to avoid risks or to minimize the consequences of disease once it occurs. 
Table 5. Assigned Subcategories of Drivers of Health and Equity in Selected Frameworks

\begin{tabular}{|c|c|c|c|c|c|c|c|c|c|c|c|}
\hline \multirow[b]{2}{*}{ Years } & \multirow[b]{2}{*}{$\begin{array}{l}\text { Organization } \\
\text { or author(s) }\end{array}$} & \multicolumn{7}{|c|}{ Individual characteristics } & \multicolumn{3}{|c|}{ Community conditions and context } \\
\hline & & $\begin{array}{c}\text { Awareness/ } \\
\text { beliefs/ } \\
\text { worldview }\end{array}$ & $\begin{array}{c}\text { Biological } \\
\text { and } \\
\text { genetics }\end{array}$ & $\begin{array}{c}\text { Health } \\
\text { behaviors }\end{array}$ & $\begin{array}{l}\text { Individual } \\
\text { experience/ } \\
\text { identity/ } \\
\text { social } \\
\text { position }\end{array}$ & $\begin{array}{c}\text { Individual } \\
\text { experience- } \\
\text { life } \\
\text { course }\end{array}$ & $\begin{array}{c}\text { Psychosocial/ } \\
\text { risk, } \\
\text { resilience/ } \\
\text { sense } \\
\text { of belonging }\end{array}$ & Socioeconomic & $\begin{array}{l}\text { Community } \\
\text { assets }\end{array}$ & $\begin{array}{l}\text { Community } \\
\text { assets- } \\
\text { health care }\end{array}$ & $\begin{array}{c}\text { Characteristics } \\
\text { of assets/ } \\
\text { services }\end{array}$ \\
\hline 2001 & 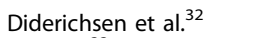 & 0 & 0 & 0 & 1 & 0 & 0 & 0 & 0 & 0 & 0 \\
\hline 2001 & Starfield ${ }^{33}$ & 0 & 0 & 0 & 0 & 0 & 0 & 0 & 1 & 1 & 0 \\
\hline 2003 & Community Guide 34 & 0 & 0 & 0 & 0 & 0 & 0 & 0 & 1 & 1 & 0 \\
\hline 2004 & Schulz and Northridge ${ }^{19}$ & 0 & 0 & 1 & 1 & 0 & 1 & 1 & 1 & 1 & 1 \\
\hline 2008 & $\mathrm{CDC}^{21}$ & 0 & 0 & 0 & 0 & 0 & 0 & 0 & 0 & 0 & 0 \\
\hline 2010 & BARHII $^{7}$ & 0 & 0 & 1 & 1 & 0 & 0 & 1 & 1 & 1 & 1 \\
\hline 2010 & $\mathrm{CSDH}^{6}$ & 0 & 0 & 0 & 1 & 0 & 0 & 1 & 1 & 1 & 0 \\
\hline 2010 & $\mathrm{CRSIHS}^{37}$ & 0 & 1 & 0 & 1 & 0 & 0 & 1 & 1 & 0 & 0 \\
\hline 2010 & $\mathrm{WHO}^{38}$ & 0 & 0 & 0 & 1 & 1 & 0 & 0 & 0 & 0 & 0 \\
\hline 2011 & $\mathrm{HI} \mathrm{DOH}^{39}$ & 0 & 1 & 1 & 1 & 0 & 0 & 1 & 1 & 1 & 0 \\
\hline 2011 & Prevention Institute ${ }^{40}$ & 0 & 0 & 0 & 1 & 0 & 0 & 0 & 1 & 0 & 0 \\
\hline 2012 & VA DOH ${ }^{41}$ & 0 & 1 & 1 & 1 & 0 & 0 & 0 & 1 & 0 & 0 \\
\hline 2013 & NHS Scotland ${ }^{42}$ & 0 & 0 & 1 & 1 & 1 & 1 & 1 & 1 & 0 & 1 \\
\hline 2013 & WRHA ${ }^{23}$ & 0 & 0 & 0 & 0 & 1 & 0 & 1 & 1 & 1 & 1 \\
\hline 2015 & $\mathrm{CO} \mathrm{DPH}{ }^{25}$ & 0 & 1 & 1 & 1 & 0 & 0 & 1 & 1 & 1 & 0 \\
\hline 2015 & Harris County, $\mathrm{TX}^{43}$ & 1 & 0 & 1 & 1 & 0 & 1 & 1 & 1 & 1 & 1 \\
\hline 2015 & $\mathrm{NIA}^{44}$ & 1 & 0 & 1 & 1 & 0 & 1 & 1 & 0 & 1 & 0 \\
\hline 2015 & NIMHHD ${ }^{24}$ & 0 & 0 & 0 & 1 & 0 & 1 & 0 & 1 & 1 & 1 \\
\hline 2015 & $\mathrm{PHAC}^{20}$ & 0 & 0 & 1 & 1 & 0 & 1 & 1 & 1 & 0 & 0 \\
\hline 2015 & RWJF $^{45}$ & 1 & 0 & 0 & 1 & 0 & 1 & 0 & 0 & 1 & 0 \\
\hline 2015 & VicHealth $^{22}$ & 1 & 0 & 0 & 1 & 1 & 0 & 1 & 1 & 1 & 0 \\
\hline 2017 & NASEM $^{46}$ & 0 & 0 & 0 & 0 & 0 & 0 & 1 & 1 & 1 & 0 \\
\hline 2017 & $\mathrm{PHAC}^{47}$ & 0 & 0 & 0 & 0 & 1 & 0 & 0 & 1 & 1 & 0 \\
\hline 2019 & $\mathrm{PAHO}^{48}$ & 0 & 0 & 0 & 1 & 1 & 0 & 1 & 1 & 0 & 0 \\
\hline 2019 & ChangeLab ${ }^{49}$ & 0 & 0 & 0 & 0 & 0 & 0 & 0 & 0 & 0 & 0 \\
\hline 2019 & Dover and Belon 50 & 0 & 0 & 0 & 1 & 0 & 1 & 1 & 1 & 0 & 1 \\
\hline \multirow[t]{2}{*}{2019} & NIMHHD ${ }^{51}$ & 1 & 0 & 1 & 1 & 0 & 1 & 1 & 1 & 1 & 1 \\
\hline & Total & 5 & 4 & 10 & 20 & 6 & 9 & 16 & 21 & 16 & 8 \\
\hline
\end{tabular}

Note: 1 = Subcategory included in framework

$0=$ Subcategory not included in framework.

4. The association between a fundamental cause and health is reproduced over time by the replacement of intervening mechanisms.

They believed that the reason for such persistent associations, and the essential feature of fundamental social causes, was that they involve access to resources that can be used to avoid risks or to minimize the consequences of disease once it occurs. They defined resources broadly to include money, knowledge, power, prestige, and beneficial social connections (social support and social networks). They have since suggested that there may be additional "fundamental causes" that include freedom, racism, discrimination, and stigma. ${ }^{28,29}$

Our examination of current frameworks for health and equity included in this study revealed several commonalities in the conceptual elements, such as community conditions and context, which have been increasingly understood as the social determinants of health. Interestingly, there was more variation in conceptual elements that extended health determinants into the realm of equity determinants. For example, only five frameworks included political or institutional power as drivers of health and equity and only two explicitly mentioned prejudice and stigma.

As noted above, nine of the frameworks identified some drivers as "fundamental" or "root" causes of health inequity. In addition to the fundamental causes suggested by Link and Phelan, ${ }^{27}$ Phelan and Link, ${ }^{28}$ and Hatzenbuehler et al., ${ }^{29}$ other potential candidates identified from these frameworks include political, governance, and economic context; legal norms; and societal values. Several of the frameworks also added more specificity to the concept of power, including political and institutional power.

Notably, neither classic nor familiar models of the social determinants of health, such as Evans and Stoddart, ${ }^{1}$ the America's Health Rankings, ${ }^{13}$ and the County Health Rankings, ${ }^{12}$ were included because they include no explicit acknowledgment of equity. As Krieger $^{30}$ pointed out, the determinants of health and the determinants of health inequalities are not necessarily the same. She argued for visual models that "clearly and unequivocally delineate the social facts of skewed distributions of power and resources and depict the societal processes that generate and maintain these distributions 


\begin{tabular}{|c|c|c|c|c|c|c|c|c|c|c|c|}
\hline \multicolumn{3}{|c|}{ Community conditions and context } & \multicolumn{6}{|c|}{ Societal context } & \multicolumn{3}{|c|}{ Overarching } \\
\hline $\begin{array}{l}\text { Environment- } \\
\text { built or } \\
\text { natural }\end{array}$ & $\begin{array}{c}\text { Environment- } \\
\text { economic } \\
\text { and } \\
\text { employment }\end{array}$ & $\begin{array}{l}\text { Environment- } \\
\text { social, } \\
\text { political, } \\
\text { cultural, } \\
\text { and history }\end{array}$ & $\begin{array}{c}\text { Civic } \\
\text { muscle }\end{array}$ & $\begin{array}{l}\text { Crisis and } \\
\text { chronic } \\
\text { conditions }\end{array}$ & $\begin{array}{l}\text { Environment- } \\
\text { economic/ } \\
\text { employment }\end{array}$ & $\begin{array}{c}\text { Environment- } \\
\text { social, } \\
\text { political, } \\
\text { and cultural }\end{array}$ & $\begin{array}{l}\text { Policies } \\
\text { and law }\end{array}$ & $\begin{array}{l}\text { Societal } \\
\text { values/ } \\
\text { norms }\end{array}$ & $\begin{array}{c}\text { Drivers of } \\
\text { inequities- } \\
\text { fundamental }\end{array}$ & $\begin{array}{l}\text { Resources } \\
\quad \text { and } \\
\text { allocation }\end{array}$ & Rights \\
\hline 0 & 0 & 1 & 0 & 0 & 0 & 1 & 1 & 0 & 1 & 0 & 0 \\
\hline 1 & 0 & 0 & 0 & 0 & 0 & 1 & 1 & 0 & 0 & 0 & 0 \\
\hline 1 & 1 & 1 & 1 & 0 & 1 & 1 & 0 & 1 & 0 & 1 & 0 \\
\hline 1 & 1 & 1 & 1 & 1 & 1 & 1 & 1 & 1 & 1 & 1 & 1 \\
\hline 1 & 0 & 0 & 0 & 0 & 1 & 0 & 0 & 0 & 0 & 0 & 0 \\
\hline 1 & 1 & 1 & 1 & 0 & 0 & 1 & 1 & 0 & 0 & 0 & 0 \\
\hline 1 & 0 & 1 & 1 & 0 & 1 & 1 & 1 & 0 & 1 & 1 & 0 \\
\hline 1 & 1 & 1 & 0 & 0 & 1 & 1 & 1 & 0 & 0 & 1 & 0 \\
\hline 1 & 1 & 1 & 0 & 0 & 0 & 1 & 0 & 0 & 1 & 0 & 0 \\
\hline 1 & 1 & 1 & 0 & 1 & 0 & 1 & 0 & 0 & 0 & 0 & 0 \\
\hline 1 & 1 & 1 & 1 & 0 & 0 & 1 & 0 & 1 & 0 & 0 & 0 \\
\hline 1 & 1 & 0 & 1 & 0 & 0 & 0 & 0 & 0 & 0 & 1 & 0 \\
\hline 1 & 1 & 1 & 1 & 0 & 0 & 0 & 0 & 1 & 1 & 1 & 0 \\
\hline 0 & 1 & 1 & 1 & 1 & 1 & 0 & 0 & 1 & 0 & 0 & 1 \\
\hline 1 & 1 & 1 & 1 & 1 & 0 & 0 & 0 & 0 & 0 & 1 & 0 \\
\hline 1 & 1 & 1 & 0 & 0 & 0 & 1 & 1 & 0 & 1 & 1 & 0 \\
\hline 0 & 1 & 1 & 1 & 1 & 0 & 1 & 0 & 1 & 1 & 0 & 0 \\
\hline 1 & 1 & 1 & 1 & 1 & 0 & 0 & 1 & 1 & 0 & 0 & 0 \\
\hline 0 & 0 & 1 & 1 & 1 & 0 & 1 & 1 & 1 & 0 & 1 & 0 \\
\hline 1 & 1 & 1 & 1 & 0 & 0 & 0 & 1 & 1 & 0 & 0 & 0 \\
\hline 1 & 0 & 1 & 1 & 0 & 0 & 1 & 0 & 1 & 0 & 0 & 0 \\
\hline 1 & 1 & 1 & 1 & 0 & 0 & 0 & 0 & 1 & 0 & 0 & 0 \\
\hline 1 & 1 & 1 & 0 & 0 & 0 & 0 & 0 & 0 & 0 & 0 & 0 \\
\hline 1 & 0 & 1 & 0 & 1 & 1 & 1 & 0 & 0 & 1 & 0 & 0 \\
\hline 0 & 1 & 1 & 0 & 1 & 0 & 0 & 0 & 0 & 0 & 1 & 0 \\
\hline 0 & 0 & 1 & 0 & 0 & 0 & 1 & 1 & 0 & 0 & 0 & 0 \\
\hline 1 & 1 & 1 & 0 & 1 & 0 & 1 & 0 & 0 & 0 & 0 & 0 \\
\hline 21 & 19 & 24 & 15 & 10 & 7 & 17 & 11 & 11 & 8 & 10 & 2 \\
\hline
\end{tabular}

and their embodiment in population levels and distributions of health, disease, and well-being" (p. 1103).

The fact that causes identified as fundamental more than two decades ago ${ }^{28}$ are not consistently incorporated into our population health and equity frameworks has implications for our practice and research, and ultimately for our progress on persistent and in some cases growing health inequities. The variation across frameworks implies that the field of population health research and practice has yet to reach consensus on the determinants of health and equity and signals a nascent health equity field.

There are formative questions regarding the variation in and relationships among conceptual elements that could help the field move closer to consensus. To name a few, Are there additional criteria for fundamental causes beyond those offered in fundamental cause theory? Or criteria that distinguish determinants of health from determinants of equity? If health behaviors illustrate individual choices based on the opportunities we have, how does this fit into health and equity frameworks? And how can we measure complex overarching concepts, such as culture or power?

As noted in the introduction, this analysis does not represent an exhaustive catalog of frameworks and mod- els of the drivers of health and equity nor is it designed as a formal evaluation of them. It also does not meet the strict criteria for a systematic review, for example, we did not record every framework that was derived from other frameworks (such as those from WHO $\mathrm{CSDH}^{6}$ or $\mathrm{BARHII}^{7}$ ) that we had already found. Specifically, although the image search proved helpful in locating additional frameworks, it captured many complete or partial duplicates. Other weaknesses of not having done a fully systematic search and review include a potentially biased selection of frameworks with a bias from the potential to omit, oversimplifying the content of frameworks, and the fact that for qualitative reviews, there is far more debate about what methods and approaches are appropriate. ${ }^{31}$

Another limitation beyond the challenges of obtaining a comprehensive set of frameworks was that our assessment of the frameworks was inherently subjective, although we tried to minimize this by using dual coding along with an independent arbiter for the tables where we summarized information from the frameworks. Our list of key elements was developed based on the criteria by the $\mathrm{CCSDH}^{3}$ and the criteria our organization's health equity work group had compiled when considering the desired attributes of a new framework. Thus, the list itself 
is subjective and may not be applicable to others who wish to develop new frameworks. For example, an anonymous reviewer questioned why we did not include asset-based approaches or issues of power and resources in our key elements. We did originally include assetbased approaches as a key element, but although some think this is desirable, asset-based approaches may not be able to appropriately acknowledge deeply entrenched drivers of inequity, such as historical trauma. So, in the end, we did not consider it to be "key." Regarding issues of power and resources that we believe are fundamental drivers, our notion of key elements was based on potentially desirable characteristics of frameworks rather than as a list of specific drivers of health and equity.

Finally, although this article is about graphical depictions, we acknowledge that the article itself does not contain any pictures! Nor does the article focus on the graphical nature of the models (beyond simple characteristics such as showing interactions). Instead, our interest in this review was primarily on the content of the graphical depictions in terms of the types of drivers of health and equity that are presented.

\section{Conclusions}

This review was conducted as part of an effort to develop a broader framework that reflects the drivers of health and the distribution of health within communities. We believe that this is a necessary step for the field of population health as we strive to be more equity focused and before identifying types of policies, systems changes, practices, and other actions that might improve health and equity outcomes. The range of action-oriented frameworks not captured in this analysis is also important and future work will be needed to minimize disconnects between driver-oriented and action-oriented frameworks.

Frameworks can be influential tools for advancing health and equity. However, the frameworks we examined were not consistent in their inclusion of the potential categories or dimensions of drivers of health and equity. As a result, they do not offer conceptual clarity on what shapes health and equity for the field of population health. This article highlights the variation in purposes, concepts, drivers, underlying theory or scholarly evidence, and accompanying measures put forth in current health and equity frameworks. Some variation is expected as it is difficult for any framework to be all things to all people. However, keeping in mind the importance of audience and purpose, the field of population health research and practice can work toward greater conceptual clarity on the drivers of health and equity. While numerous graphic representations of population health and equity exist, further work to visually represent underlying theories that drive value-based assessment of equity needs focused attention if we are to collectively advance our efforts for health and equity.

\section{Acknowledgments}

This work was funded by the School of Medicine and Public Health, University of Wisconsin-Madison.

\section{Author Disclosure Statement}

No competing financial interests exist.

\section{Funding Information}

No external funding was provided.

\section{References}

1. Evans RG, Stoddart GL. Producing health, consuming health care. Soc Sci Med. 1990;31:1347-1363.

2. Dahlgren G, Whitehead M. Policies and Strategies to Promote Social Equity in Health. Stockholm, Sweden: Institute for Futures Studies, 1991.

3. Canadian Council on Social Determinants of Health. A Review of Frameworks on the Determinants of Health. Ottawa, ON: Canadian Council on Social Determinants of Health, 2015. Available at http://ccsdh.ca/images/ uploads/Frameworks_Report_English.pdf Accessed December 13, 2019.

4. McCartney G, Popham F, McMaster R, et al. Defining health and health inequalities. Public Health. 2019;172:22-30.

5. Whitehead M. The concepts and principles of equity and health. Int J Health Services. 1992;22:429-445.

6. Solar O, Irwin A. A conceptual framework for action on the social determinants of health. Social Determinants of Health Discussion Paper 2 (Policy and Practice), 2010. Available at https://www.who.int/ sdhconference/resources/ConceptualframeworkforactiononSDH_eng .pdf Accessed February 13, 2020.

7. Bay Area Regional Health Inequity Initiative (BARHII) Framework. Available at http://barhii.org/framework Accessed December 13, 2019.

8. Davison CM, Ndumbe-Eyoh S, Clement C. Critical examination of knowledge to action models and implications for promoting health equity. Int J Equity Health. 2015;14:49.

9. Framework. In Merriam-Webster.com. 2019. Available at https://www .merriam-webster.com/dictionary/framework Accessed December 13, 2019.

10. Model. In Merriam-Webster.com. 2019. Available at https://www.merriamwebster.com/dictionary/model Accessed December 13, 2019.

11. Frieden TR. A framework for public health action: the health impact pyramid. Am J Public Health. 2010;100:590-595.

12. University of Wisconsin Population Health Institute. County Health Rankings Model. Available at www.countyhealthrankings.org Accessed February 14, 2020.

13. United Health Foundation. America's Health Ranking Model. Available at https://www.americashealthrankings.org/about/methodology/ introduction Accessed February 14, 2020.

14. Well Being in the Nation (WIN). Vital Conditions for Wellbeing. Available at https://winnetwork.org/about/vital-conditions Accessed December 1, 2019.

15. Wellbeing in the Nation Network. About WIN Measures. Available at https://www.winmeasures.org/statistics/winmeasures Accessed December 1, 2019.

16. Chang W-C. The meaning and goals of equity in health. J Epidemiol Community Health. 2002;56:488-491.

17. King County, Washington. 14 Determinants of Health Equity. April 2015. Available at https://www.kingcounty.gov/elected/executive/constantine/ priorities/building-equity/infographic.aspx Accessed March 19, 2019.

18. Gee GC, Payne-Sturges DC. Environmental health disparities: a framework integrating psychosocial and environmental concepts. Environ Health Perspect. 2004;112:1635-1653.

19. Schulz A, Northridge ME. Social determinants of health: implications for environmental health promotion. Health Educ Behav. 2004;31:455-471. 
20. Public Health Agency of Canada. Toward Health Equity: A Tool for Developing Equity-Sensitive Public Health Interventions. 2015. Available at http: //nccdh.ca/resources/entry/toward-health-equity-a-tool-for-developingequity-sensitive-public-health-i Accessed May 6, 2019.

21. Brennan Ramirez LK, Baker EA, Metzler M. Promoting Health Equity: $A$ Resource to Help Communities Address Social Determinants of Health. Atlanta, GA: U.S. Department of Health and Human Services, Centers for Disease Control and Prevention, 2008.

22. VicHealth. Fair Foundations: The VicHealth Framework for health equity. 2015. Available at https://www.vichealth.vic.gov.au/-/media/ ResourceCentre/PublicationsandResources/Health-Inequalities/FairFoundations/Web-Fair-Foundation-VicHealth-framework-for-healthequity.pdf?la=en\&hash=EA5BFE306E2F0BA74406C8DBA459BF0650C1E3F7 Accessed May 6, 2019.

23. Winnipeg Regional Health Authority. Health for All: Building Winnipeg's Health Equity Action Plan. 2013. Available at http://www.wrha.mb.ca/ about/healthequity/files/HealthForAll_Documentwithlinks.pdf Accessed May 6, 2019.

24. Alvidrez J, Castille D, Laude-Sharp $M$, et al. The National Institute of Minority Health and Health research framework. Am J Public Health. 2019; 109(S1):S16-S20.

25. Colorado Department of Public Health and Environment. Health Equity: An Explanatory Model for Conceptualizing the Social Determinants of Health. 2015. Available at www.colorado.gov/pacific/sites/default/files/ OHE_Health-Equity-Model.pdf Accessed May 6, 2019.

26. Foot J. What makes us healthy? The asset approach in practice: Evidence, action, evaluation. 2012. Available at http://www.janefoot.co.uk/downloads/ files/healthy\%20FINAL\%20FINAL.pdf Accessed February 27, 2020.

27. Link BG, Phelan J. Social conditions as fundamental causes of disease. J Health Soc Behav. 1995;(Spec No.): 80-94.

28. Phelan JC, Link BG. Is racism a fundamental cause of inequalities in health? Annu Rev Sociol. 2015;41:311-330.

29. Hatzenbuehler ML, Phelan JC, Link BG. Stigma as a fundamental cause of population health inequalities. Am J Public Health. 2013;103:813-821.

30. Krieger N. Ladders, pyramids and champagne: the iconography of health inequities. J Epidemiol Community Health. 2008;62:1098-1104.

31. Grant MJ, Booth A. A typology of reviews: an analysis of 14 review types and associated methodologies. Health Info Libr J. 2009;26:91-108.

32. Diderichsen F, Evans T, Whitehead M. Chapter 2: The social basis of disparities in health. Challenging Inequities in Health: From Ethics to Actions. Edited by Evans T, Whitehead M, Diderichsen F, et al. New York: Oxford University Press, 2001.

33. Starfield B. Improving equity in health: a research agenda. Int Journal Health Serv. 2001;31:545-566.

34. Anderson LM, Fielding JE, Fullilove MT, et al. Methods for conducting systematic reviews of the evidence of effectiveness and economic efficiency of interventions to promote healthy social environments. Am J Prev Med. 2003;24(3S):25-31.

35. Schulz AJ, Williams DR, Israel BA, Lempert LB. Racial and spatial relations as fundamental determinants of health in Detroit. Milbank Q. 2002;80:677-707.

36. Northridge ME, Sclar E. A joint urban planning and public health framework: contributions to health impact Assessment. Am J Public Health. 2003;93:118-121.

37. Borrell C, Malmusi D, Muntaner C. Introduction to the "Evaluating the impact of structural policies on health inequalities and their social determinants and fostering change" (SOPHIE) Project. Int J Health Serv. 2017;47:10-17.

38. Blas E, Kurup AS, Editors. Equity, Social Determinants and Public Health Programmes. World Health Organization. 2010. Available at https://www .who.int/sdhconference/resources/EquitySDandPH_eng.pdf Accessed May 9, 2019.

39. Hawai'i State Department of Health: Chronic Disease Management and Control Branch. Chronic Disease Disparities Report 2011: Social Determinants. 2011. Available at http://health.hawaii.gov/chronic-disease/files/ 2013/12/CD_BurdenReport_FINAL.pdf Accessed May 6, 2019.

40. Prevention Institute. Making the Case with THRIVE: Background Research on Community Determinants of Health. Available at https://www .preventioninstitute.org/sites/default/files/uploads/Making\%20the\% 20case\%20with\%20THRIVE\%20Nov\%202015.pdf Accessed May 8, 2019.

41. Virginia Department of Health. Virginia Health Equity Report 2012. Available at http://www.vdh.virginia.gov/content/uploads/sites/76/2016/06/ Health-Equity-Report-2012.pdf Accessed May 6, 2019
42. Beeston C, McCartney G, Ford J, et al. Health Inequalities Policy Review for the Scottish Ministerial Task Force on Health Inequalities. NHS Health Scotland: Edinburgh, 2014. Available at http://www.healthscotland.scot/ media/1053/1-healthinequalitiespolicyreview.pdf Accessed May 8, 2019.

43. Harris County Public Health. Health Equity Framework. 2015. Available at https://publichealth.harriscountytx.gov/Portals/27/Documents/ Organization/OPP/Health_Equity_Framework.png Accessed May 6, 2019. 44. Hill CV, Perez-Stable EJ, Anderson NA, et al. The National Institute on Aging Health Disparities research framework. Ethn Dis. 2015;25:245-254. 45. Plough A, Miller C, Tait M, et al. Moving Forward Together: An Update on Building and Measuring a Culture of Health. Princeton NJ: Robert Wood Johnson Foundation, 2018. Available at https://www.rwjf.org/content/ dam/COH/PDFs/MovingForwardTogetherFullReportFinal.pdf Accessed May 8, 2019.

46. National Academies of Sciences, Engineering, and Medicine. Communities in Action: Pathways to Health Equity. Washington, DC: The National Academies Press, 2017. Available at https://www.nap.edu/catalog/24624/ communities-in-action-pathways-to-health-equity Accessed May 6, 2019.

47. Pan-Canadian Health Inequities Data Tool, 2017 Edition. A joint initiative of the Public Health Agency of Canada, the Pan-Canadian Public Health Network, Statistics Canada, and the Canadian Institute of Health Information. Available at https://infobase.phac-aspc.gc.ca/health-inequalities/ data-tool Accessed May 6, 2019.

48. Pan-American Health Organization. Just Societies: Health Equity and Dignified Lives. Executive Summary of the Report of the Commission of the Pan American Health Organization on Equity and Health Inequalities in the Americas. Washington, DC: PAHO, 2018. Available at http://iris.paho.org/ xmlui/bitstream/handle/123456789/49505/9789275120217_eng .pdf?sequence=3\&isAllowed=y Accessed May 6, 2019.

49. ChangeLab Solutions. A Blueprint for Changemakers: Achieving Health Equity Through Law and Policy. 2019. Available at https://www .changelabsolutions.org/product/blueprint-changemakers Accessed February 16, 2020.

50. Dover DC, Belon AP. The health equity measurement framework: a comprehensive model to measure social inequities in health. Intl J Equity Health. 2019;18:36.

51. Duran DG, Perez-Stable. Novel approaches to advance minority health and health disparities research. Am J Public Health. 2019;109(S1):S8-S10.

Cite this article as: Givens ML, Catlin BB, Johnson SP, Pollock EA, Faust VN, Inzeo PT, Kindig DA (2020) What do we know about the drivers of health and equity? A narrative review of graphic representations, Health Equity 4:1, 446-462, DOI: 10.1089/heq.2020.0013.

$\begin{aligned} & \text { Abbreviations Used } \\ & \text { BARHII }=\text { Bay Area Regional Health Inequities Initiative } \\ & \mathrm{CCSDH}=\text { Canadian Council on Social Determinants of Health } \\ & \mathrm{CDC}=\text { Centers for Disease Control and Prevention } \\ & \mathrm{CO} D \mathrm{DH}=\text { Colorado Department of Public Health } \\ & \mathrm{CRSIHS}=\text { Commission to Reduce Social Inequalities in Health in Spain } \\ & \mathrm{CSDH}=\text { Commission on the Social Determinants of Health } \\ & \mathrm{HEMF}=\text { Health Equity Measurement Framework } \\ & \mathrm{HI} \mathrm{DOH}=\text { Hawai'i State Department of Health } \\ & \mathrm{NACA}=\text { National Advisory Council on Aging } \\ & \mathrm{NASEM}=\text { National Academies of Sciences, Engineering, and Medicine } \\ & \mathrm{NIA}=\text { National Institute on Aging } \\ & \mathrm{NIMHD}=\text { National Institute of Minority Health and Health Disparities } \\ & \mathrm{PAHO}=\text { Pan-American Health Organization } \\ & \mathrm{PHAC}=\text { Public Health Agency of Canada } \\ & \mathrm{RWJF}=\text { Robert Wood Johnson Foundation } \\ & \mathrm{SDH}=\text { Social Determinants of Health } \\ & \mathrm{SOPHIE}=\text { Structural Policies for Health Inequalities Evaluation } \\ & \text { THRIVE }=\text { Tool for Health and Resilience in Vulnerable Environments } \\ & \mathrm{VA} \mathrm{DOH}=\text { Virginia Department of Health } \\ & \text { WHO }=\text { World Health Organization } \\ & \text { WRHA }=\text { Winnipeg Regional Health Authority } \\ &\end{aligned}$

